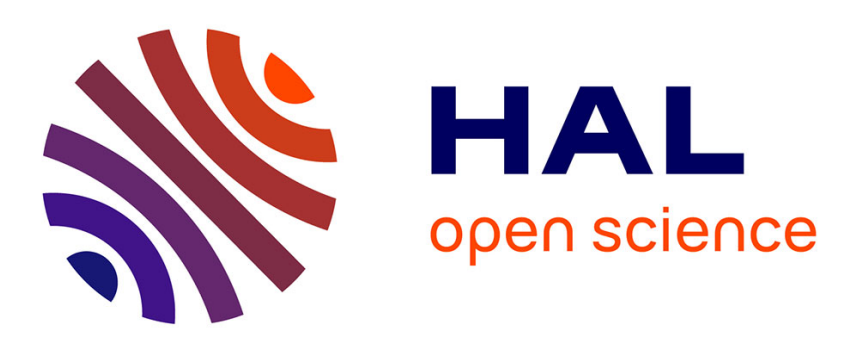

\title{
Synergistic activity of letrozole and sorafenib on breast cancer cells
}

\author{
Mara A. Bonelli, Claudia Fumarola, Roberta R. Alfieri, Silvia Monica, Andrea
}

Cavazzoni, Maricla Galetti, Rita Gatti, Silvana Belletti, Adrian L. Harris, Stephen B. Fox, et al.

\section{To cite this version:}

Mara A. Bonelli, Claudia Fumarola, Roberta R. Alfieri, Silvia Monica, Andrea Cavazzoni, et al.. Synergistic activity of letrozole and sorafenib on breast cancer cells. Breast Cancer Research and Treatment, 2010, 124 (1), pp.79-88. 10.1007/s10549-009-0714-5 . hal-00526203

\section{HAL Id: hal-00526203 https://hal.science/hal-00526203}

Submitted on 14 Oct 2010

HAL is a multi-disciplinary open access archive for the deposit and dissemination of scientific research documents, whether they are published or not. The documents may come from teaching and research institutions in France or abroad, or from public or private research centers.
L'archive ouverte pluridisciplinaire HAL, est destinée au dépôt et à la diffusion de documents scientifiques de niveau recherche, publiés ou non, émanant des établissements d'enseignement et de recherche français ou étrangers, des laboratoires publics ou privés. 
SYNERGISTIC ACTIVITY OF LETROZOLE AND SORAFENIB ON BREAST CANCER CELLS

Mara A. Bonelli ${ }^{1{ }^{*}}$, Claudia Fumarola ${ }^{1 *}$, Roberta R. Alfieri ${ }^{1}$, Silvia La Monica ${ }^{1}$, Andrea Cavazzoni ${ }^{1}$, Maricla Galetti ${ }^{1}$, Rita Gatti ${ }^{1}$, Silvana Belletti ${ }^{1}$, Adrian L. Harris ${ }^{2}$, Stephen B. Fox $^{3}$, Dean B. Evans ${ }^{4}$, Mitch Dowsett ${ }^{5}$, Lesley-Ann Martin ${ }^{6}$, Alberto Bottini ${ }^{7}$, Daniele Generali $^{7,8}$, Pier Giorgio Petronini ${ }^{1}$

${ }^{1}$ Department of Experimental Medicine, University of Parma, Italy

${ }^{2}$ Molecular Oncology Laboratories, Weatherall Institute of Molecular Medicine, University of Oxford, John Radcliffe Hospital, Oxford, UK

${ }^{3}$ Peter MacCallum Cancer Centre, St Andrews Place, East Melbourne, Victoria, Australia

${ }^{4}$ Novartis Institutes of BioMedical Research, Oncology Research, Basel, Switzerland

${ }^{5}$ Academic Department of Biochemistry, Royal Marsden Hospital; ${ }^{6}$ Breakthrough Breast Cancer Centre, Institute of Cancer Research, London, UK

${ }^{7}$ Unità di Patologia Mammaria-Breast Cancer Unit; ${ }^{8}$ Centro di Medicina Molecolare, Istituti Ospitalieri di Cremona, Italy

*These authors contributed equally to this work

Running title: Letrozole and sorafenib combination in breast cancer cells.

Keywords: letrozole, sorafenib, breast cancer, mTORC1

Footnote: Dean Evans is employed by Novartis Pharma AG

Grant support: Associazione Davide Rodella, Montichiari (BS); Lega Italiana per la lotta contro i tumori, Parma; A.VO.PRO.RI.T., Parma; Fondazione Banca Popolare di Cremona; CONAD, Bologna (Italy)

Requests for reprints:

Claudia Fumarola

Department of Experimental Medicine

Via Volturno, 39

43100 Parma (Italy)

Phone: +390521903762

Fax: +390521903742

e-mail: claudia.fumarola@unipr.it 


\section{ABSTRACT}

Estrogens induce breast tumour cell proliferation by directly regulating gene expression via the estrogen receptor (ER) transcriptional activity and by affecting growth factor signalling pathways such as mitogen-activated protein kinase (MAPK) and AKT/mammalian target of rapamycin Complex1 (mTORC1) cascades. In this study we demonstrated the preclinical therapeutic efficacy of combining the aromatase inhibitor letrozole with the multi-kinase inhibitor sorafenib in aromatase-expressing breast cancer cell lines. Treatment with letrozole reduced testosterone-driven cell proliferation, by inhibiting the synthesis of estrogens. Sorafenib inhibited cell proliferation in a concentration-dependent manner; this effect was not dependent on sorafenib-mediated inhibition of Raf1, but involved the downregulation of $\mathrm{mTORC} 1$ and its targets $\mathrm{p} 70 \mathrm{~S} 6 \mathrm{~K}$ and $4 \mathrm{E}$-binding protein 1 (4E-BP1). At concentrations of $5-10 \mu \mathrm{M}$ the growth-inhibitory effect of sorafenib was associated with the induction of apoptosis, as indicated by release of cytochrome $c$ and Apoptosis-Inducing Factor into the cytosol, activation of caspase-9 and caspase-7, and PARP-1 cleavage.

Combination of letrozole and sorafenib produced a synergistic inhibition of cell proliferation associated with an enhanced accumulation of cells in the $G_{0} / G_{1}$ phase of the cell cycle and with a down-regulation of the cell cycle regulatory proteins c-myc, cyclin D1 and phosphoRb. In addition, longer experiments (12 weeks) demonstrated that sorafenib may be effective in preventing the acquisition of resistance towards letrozole. Together, these results indicate that combination of letrozole and sorafenib might constitute a promising approach to the treatment of hormone-dependent breast cancer. 


\section{INTRODUCTION}

Approximately $60 \%$ of primary breast cancers express the ER-alpha and are dependent on estrogens for their growth. ER is a member of the nuclear hormone receptor superfamily and $17 \beta$-estradiol (E2) is the most potent ligand. Estrogens activate ER through genomic and non-genomic pathways, stimulating nuclear and cytoplasmatic processes that promote breast cancer cell proliferation. In the nucleus, ER regulates gene transcription either by direct binding to estrogen response elements (ERE) [1] or via protein-protein interactions with other transcription factors such as AP-1, SP-1, and NF-kB [2]. In addition, estrogens exert rapid non-genomic actions mediated by the interaction between membrane-bound ER and membrane kinase receptors such as IGF-IR, EGFR, and HER2 [1], which results in the activation of signalling cascades including the Ras/Raf/MAPK pathway [3] and the phosphatidylinositol-3-kinase (PI3K)/AKT/mTOR pathway [2]. Conversely, ER can be directly activated in the absence of estrogens by various kinases, including MAPK and PISK/AKT $[4,5]$.

In postmenopausal women, estrogens are generated from androgens through aromatasedependent enzymatic conversion [6]. Letrozole $\left(\right.$ Femara $\left.^{\circledR}\right)$ is a third-generation nonsteroidal aromatase inhibitor (Al) [7] approved for treatment of postmenopausal women with hormone-dependent breast cancer. By eradicating estrogens, Als suppress both genomic and non-genomic action of ER and are proved to be effective as first-line therapy in advanced/metastatic breast cancer as well as in neoadjuvant, early adjuvant and extended adjuvant strategies [8]. However, either intrinsic or acquired resistance to Als may occur, arising from activation of novel signalling mechanisms that involve crosstalk between ER and growth factor receptors [9]. This provides a strong rationale for combining endocrine therapies with signal transduction inhibitors to achieve a more potent antitumour effect or to bypass acquired resistance $[10,11]$. 
Generali and co-workers demonstrated the role of mTOR, MAPK and HIF-1a in endocrine resistance in patients receiving letrozole-based treatment supporting the development of new treatment strategies based on the combination of Als with signal transduction inhibitors targeting mainly MAPK but also mTOR and HIF-1alpha [12].

Sorafenib (Nexavar, BAY43-9006) is a multi-kinase inhibitor recently approved for treatment of advanced renal cell and hepatocellular carcinoma [13, 14]. It has been shown to block tumour cell proliferation and angiogenesis by inhibiting serine/threonine kinases (C-Raf, mutant and wild-type B-Raf) as well as vascular endothelial growth factor receptors (VEGFR2, VEGFR3) [15], and other tyrosine-kinase receptors such as PDGFR$\beta$, FLT-3, Ret and C-KIT $[15,16]$. In animal models, sorafenib effectively reduces melanoma, breast, colon and lung cancer growth [15, 17]. In addition, it has been reported that sorafenib induces apoptosis in a variety of tumour cell lines [18-22]. Recently, it was also shown that sorafenib modulates either mTOR signalling and its targets (p70S6K, S6R, 4EBP1) expression or HIF-1alpha expression [23, 24].

The purpose of this study was to evaluate the potential for combining letrozole and sorafenib in breast cancer cell lines constitutively expressing the aromatase gene. 


\section{MATERIALS AND METHODS}

\section{Cell culture}

The human breast cancer cell lines MCF-7/AROM-1 and T47D/AROM (clone 1 and 2), expressing high levels of aromatase, were generated by stable transfection of full-length human aromatase under control of the cytomegalovirus promoter. BT474/AROM were stably transduced with a retroviral construct pBabeAROM expressing aromatase. Cells were cultured as recommended $[25,26]$.

Before the experiments cells were steroid-deprived for 4 days using phenol red-free medium supplemented with 5\% charcoal-stripped FCS (HyClone, Logan, UT) and then treated with $1 \mathrm{nM} E 2$ or stimulated with $100 \mathrm{nM}$ testosterone $(\mathrm{T})$ in the absence or presence of the drugs. Media and drugs were changed every three days.

\section{Compounds}

Letrozole was provided by Novartis Institutes for BioMedical Research (Basel, Switzerland). Sorafenib was from Bayer HealthCare LLC (Tarrytown, NY). Drugs and hormones (E2 and T, Sigma-Aldrich, St. Louis, MO) were prepared in DMSO. The concentration of DMSO never exceeded $0.1 \%(\mathrm{v} / \mathrm{v})$ and equal amounts of the solvent were added to control cells.

\section{Antibodies and reagents}

Media and FBS were from Euroclone (Devon, UK). Antibodies against cytochrome $c$, Apoptosis-Inducing Factor (AIF), p53, p21 ${ }^{\text {WAF1 }}$ were from Santa Cruz Biotechnology (Santa Cruz, CA). Antibodies against PARP-1, caspase-7, caspase-8, caspase-9, phospho-ERK1/2(Thr202/Tyr204), ERK1/2, phospho-AKT(Ser473), AKT, phosphomTOR(Ser2448), phospho-4E-BP1(Ser65), phospho-p70S6K(Thr389), p70S6K, c-myc, 
cyclin D1, p27 ${ }^{\mathrm{Kip} 1}$, phospho-Rb(Ser780), and Rb were from Cell Signaling Technology (Beverly, MA). Anti-actin antibody was from Sigma-Aldrich. Horseradish peroxidaseconjugated secondary antibodies and chemiluminescence system were from Millipore (Millipore, MA). Reagents for electrophoresis and blotting analysis were from BIO-RAD Laboratories (Hercules, CA). Calcein-AM and propidium iodide (PI) were from Invitrogen (Milano, Italy), Draq5 was from Alexis Biochemicals (Lausen, Switzerland). Rapamycin and all other reagents were from Sigma-Aldrich.

\section{Western blotting}

Procedures for protein extraction and analysis by 1-D PAGE are described elsewhere [27]. Cytosolic and mitochondrial fractions were generated as previously described [28].

Protein levels were quantified by densitometric analysis (UN-SCAN-IT ${ }^{\mathrm{TM}}$ gel) and normalized to the actin levels; values are expressed as percent versus T-stimulated cells.

\section{Analysis of cell proliferation, cell death and cell cycle}

Cell proliferation was evaluated by cell counting and tetrazolium dye [3-(4,5dimethylthiazol-2-yl)-2,5-diphenyltetrazolium-bromide] (MTT) assay, as previously described [27]. Data are expressed as percent inhibition of cell proliferation versus Tstimulated cells, calculated by subtracting the amount of proliferation independent of hormone stimulation. A percent value of inhibition $>100 \%$ indicates that hormoneindependent cell proliferation was also inhibited.

Cell death was assessed as previously described [28]. In addition, real time analysis was performed using a Zeiss LSM510 Meta confocal microscope (CLSM) (Carl Zeiss, Jena, Germany) with a 63X NA 1.4 plan apo objective. Viability and morphology were assessed after cell loading with calcein-AM, PI and Draq5 excited with 488, 543, 633 laser lines 
respectively. Acquisition was carried out in the multitrack mode, namely through consecutive and independent optical pathways .

Distribution of the cells in the cell cycle was determined by PI staining and flow cytometry as described elsewhere $[27,28]$.

\section{Statistical Analysis}

Statistical significance of differences among data was estimated by two-tailed Student's $t$ test or one-way ANOVA (with Tukey test for pairwise comparisons). Differences were considered significant at $p<0.05$.

$I_{50}$ values, expressed as mean of three independent determinations $( \pm S D)$, were calculated by fitting the experimental data with a hyperbolic function and constraining $Y_{\max }$ to 100 (GraphPad-Prism 4.00).

The nature of the interaction between letrozole and sorafenib was calculated using the Bliss interaction model $[29,30]$. A theoretical dose-response curve was calculated for combined inhibition using the equation $E_{\text {bliss }}=E_{A}+E_{B}-E_{A} \times E_{B}$, where $E_{A}$ and $E_{B}$ are the percent of inhibition versus testosterone-stimulated cells, obtained by drug A (sorafenib) and $B$ (letrozole) alone and $E_{b l i s s}$ is the percent of inhibition that would be expected if the combination was exactly additive. If the experimental percent of inhibition is $>E_{\text {bliss }}$ the combination is considered synergistic, if it is $<\mathrm{E}_{\text {bliss }}$ the combination is antagonistic. 


\section{RESULTS}

\section{Letrozole and sorafenib inhibit estrogen-driven proliferation of MCF-7/AROM-1 cells.}

MCF-7/AROM-1 cells were firstly analyzed for their estrogen sensitivity (fig.1a). Cell proliferation was slowed by steroid-deprivation and stimulated in a time-dependent manner by either E2 or testosterone, thus indicating that these cells mainly depend on estrogens for their growth. The effect of letrozole on cell proliferation was evaluated in testosteronestimulated cells seeded at different densities. A clear concentration-dependent inhibition of testosterone-driven proliferation was observed in cells cultured at low density (fig.1b); in contrast, in cells cultured at higher density letrozole, even at $10 \mu \mathrm{M}$, was unable to inhibit cell proliferation by more than $20 \%$, indicating that the growth-inhibitory effect of the drug is affected by cell density. Indeed, in high density cell cultures a higher concentration of autocrine growth factors is presumably achieved [31], thus rendering cell proliferation less dependent on estrogen production. Treatments with letrozole up to 6 days, even at the highest concentrations, were never associated with induction of cell death (not shown).

Then we evaluated the effects of sorafenib on testosterone-driven proliferation. As demonstrated by cell counting (not shown) and MTT assay (fig.1c), sorafenib impaired cell proliferation in a concentration-dependent manner. In addition, sorafenib inhibited ERK1/2 phosphorylation only at concentrations higher than the $\mathrm{IC}_{50}$ value $(3 \mu \mathrm{M})$ after $2 \mathrm{~h}$ of treatment, whereas the activation status of the AKT/mTORC1 pathway was unaffected (fig.1d). It is noteworthy that the range of concentrations of sorafenib here used was below the plasma concentrations achieved in vivo at the clinically approved doses [32, 33].

\section{Sorafenib at higher concentrations induces cell death by apoptosis.}

Treatment with sorafenib at higher concentrations $(5-10 \mu \mathrm{M})$ was associated with the induction of cell death (fig.2a). Flow cytometry revealed the presence of Annexin V-FITC- 
positive cells excluding $\mathrm{PI}$ at early time intervals (not shown), suggesting that sorafenib induced cell death by apoptosis. This result was confirmed by CSLM analysis (fig.2b). Sorafenib-treated cells exhibited some morphological hallmarks of apoptosis: rounded shape, nuclear condensation, blebbing and calcein-positivity until late stages [34]; the morphological changes associated with caspase-3 activity, such as fragmentation in apoptotic bodies, were not detected because MCF-7/AROM-1 cells are null for caspase-3 [35]. As shown in fig.2c sorafenib induced cleavage of the caspase substrate PARP-1 [36] and activation of the effector caspase-7. Also procaspase-9 was processed into active subunits, whereas procaspase-8 remained uncleaved, indicating that sorafenib-mediated apoptosis was associated with the activation of the mitochondrial intrinsic pathway. In line with this observation, cytochrome $c$ was detected in the cytosol (fig.2d). Concomitantly, AIF was released from the mitochondria, suggesting that activation of both caspasedependent and -independent pathways could be involved in the pro-apoptotic effects of sorafenib.

Combination of letrozole and sorafenib results in synergistic anti-proliferative activity in aromatase-expressing breast cancer cell lines.

Treatment of MCF-7/AROM-1 cells with $1 \mu \mathrm{M}$ letrozole and increasing concentrations of sorafenib $(0.1-2.5 \mu \mathrm{M})$ produced a synergystic inhibition of cell proliferation, as calculated by the Bliss interaction model (fig.3a). Combination with $5 \mu \mathrm{M}$ sorafenib failed to produce any enhancement of the growth-inhibitory effects, presumably because of the cytotoxic action of sorafenib at this concentration.

To evaluate whether the synergistic anti-proliferative action of letrozole and sorafenib required the simultaneous presence of both drugs from the start of treatment, we compared three different schedules: "simultaneous", "sequential", and "up-front" (letrozole before combination) treatment. As shown in fig.3b, the "sequential" treatment was not 
effective in enhancing the anti-proliferative activity of the single agents. In contrast, the "up-front" schedule showed the same enhanced anti-proliferative effect as that produced by the "simultaneous" schedule.

We then examined the impact of the synergistic drug treatment on growth/survival signalling pathways. As shown in fig.3c, letrozole alone had no effect on the phosphorylation/expression of ERK1/2, AKT, mTORC1 and p70S6K. In contrast, sorafenib significantly decreased the phosphorylation of mTORC1 and its targets p70S6K and 4EBP1 after 24-72h; concomitantly the phospho-AKT and phospho-ERK1/2 level increased, presumably as consequence of release of mTORC1-mediated inhibition on PISK/AKT signalling [37]. The combination with letrozole did not produce any additional effect on these changes.

To evaluate whether the synergistic anti-proliferative effect of letrozole/sorafenib combination was not restricted to MCF7/AROM-1 cells, treatments with letrozole and sorafenib either alone or in combination were performed in other aromatase-expressing breast cancer cell lines, i.e. T47D/AROM cells (clone 1 and 2) and BT474/AROM cells. As demonstrated in MCF-7/AROM-1 cells, letrozole slowed cell proliferation (fig.4a). Treatment with sorafenib inhibited cell proliferation in a concentration-dependent manner (fig.4b) and was associated with inhibition of the mTORC1 pathway (not shown); in addition induction of cell death was detected on treatment with higher concentrations of the drug (fig.4c). Most importantly, the combined treatment produced a synergistic antiproliferative effect, as demonstrated by the Bliss interaction model (fig.4d), thus strengthening the potential of combining letrozole and sorafenib for treatment of hormonedependent breast cancer.

Letrozole and sorafenib cooperate to induce $G_{0} / G_{1}$ cell cycle arrest without inducing cell death. 
Cell cycle analysis of MCF-7/AROM-1 cells (fig.5a) demonstrated that after 3 days of steroid-deprivation the cells were almost completely blocked in $\mathrm{G}_{0} / \mathrm{G}_{1}$ phase. Treatment with either letrozole or sorafenib also induced accumulation of cells in $G_{0} / G_{1}$ phase with a concomitant decrease of cells in $S$ phase. The accumulation of cells in $G_{0} / G_{1}$ phase was further increased by the drug combination, thus confirming the synergistic growth-inhibitory effects. Western blot analysis demonstrated that neither the single drug treatme nt nor the combination affected the expression of p53 and p27 (fig.5b). Letrozole induced p21 expression; however, no further induction was observed in the presence of both drugs. In contrast, a combined effect was detectable on the expression of c-myc, cyclin D1 and phospho-Rb, whose levels were reduced after 3 days of treatment. Comparable effects were obtained combining letrozole with the mTORC1 inhibitor rapamycin (fig.5b), suggesting that the down-regulation of these cell cycle regulatory proteins required the simultaneous inhibition of the estrogen-dependent signalling and the mTORC1 pathway. Fluorescence microscopy demonstrated that letrozole $1 \mu \mathrm{M}$ combined with sorafenib 1-2.5 $\mu \mathrm{M}$ up to 6 days failed to promote cell death (not shown), indicating that the drug combination had cytostatic and not cytotoxic effects.

\section{Sorafenib treatment prevents the acquisition of resistance towards letrozole.}

Acquisition of resistance to letrozole has been shown to eventually occur after prolonged treatments with the drug [38]. To evaluate whether sorafenib may prevent or delay the development of resistance to letrozole, long-lasting treatments with the single agents or the combination were performed in MCF-7/AROM-1 cells. As shown in fig.6, the proliferation index of cells continuously cultured in the presence of letrozole was lower than that observed in testosterone-stimulated cells. However, a more prolonged treatment with letrozole eventually promotes the acquisition of resistance to the drug. Also sorafenib treatment produced a decline in the proliferation index, however the cells continued to 
proliferate, although at a very low rate. In contrast, continuous treatment with letrozole and sorafenib induced a rapid decline of the proliferation index followed by death of the entire cell population ( $\mathrm{N} / \mathrm{N} 0<1$ after 9 weeks), indicating that MCF-7/AROM-1 cells were not able to adapt to the drug combination and therefore to acquire any form of resistance to letrozole. 


\section{DISCUSSION}

In recent years, crosstalk between ER and growth factor receptors has been shown to contribute to both the failure of endocrine therapy as well as the development of resistance in breast cancer. Therefore, a clear rationale has been developed for combining endocrine therapies with signal transduction inhibitors to enhance endocrine responsiveness and to potentially circumvent or delay the onset of acquired resistance $[10,11]$.

The multi-kinase inhibitor sorafenib has been recently approved for treatment of advanced renal and hepatocellular carcinoma $[13,14]$ and has shown potent activity against a variety of tumour cell types [39]. In breast cancer cells sorafenib reduces cell proliferation, and sensitizes to chemotherapy via down-regulation of the Bcl-2-like anti-apoptotic protein Mcl$1[22,40]$. Moreover, sorafenib combined with nanoliposomal ceramide has been shown to inhibit survival of MDA-MB-231 breast cancer cells and decrease tumour development in vivo [41].

Here we provide evidence that letrozole combined with sorafenib produces synergistic anti-proliferative effects in aromatase-expressing breast cancer cell lines (MCF-7/AROM-1, T47D/AROM and BT474/AROM cells).

Proliferation of these cells is affected by estrogen or testosterone stimulation and letrozole, by preventing testosterone aromatization, inhibited cell proliferation.

Also sorafenib inhibited cell proliferation in a concentration-dependent manner. It could be argued that sorafenib's anti-proliferative effect may result via direct inhibition of aromatase, however recent studies have shown this is not the case [26]. In addition, when sorafenib was used at higher concentrations $(5-10 \mu \mathrm{M})$ the inhibition of cell proliferation was associated with apoptosis induction, via the mitochondrial intrinsic pathway.

In testosterone-stimulated MCF-7/AROM-1 cells, sorafenib at $2.5 \mu \mathrm{M}$ significantly decreased the phosphorylation of mTORC1 and its targets p70S6K and 4E-BP1. A 
sorafenib-mediated inhibition of the mTOR pathway has been described in melanoma cells as a consequence of MAPK signalling inhibition and ascribed to the existence of crosstalk between MAPK and mTOR signalling [42]. Under our experimental conditions, however, inhibition of the MAPK pathway was only observed with higher concentrations of sorafenib $(5-10 \mu \mathrm{M})$, suggesting that other mechanisms are involved in the down-regulation of the mTORC1 signalling. Sorafenib-mediated inhibition of mTORC1 signalling was downstream of $\mathrm{AKT}$, being associated with AKT phosphorylation/activation. In this scenario, sorafenib seems to mimic a phenomenon that has been widely described in various cellular models, including MCF-7 cells, on treatment with rapamycin, i.e. the release of mTOR-dependent negative regulation of $\mathrm{RTK} / \mathrm{IRS}-1 / \mathrm{P} / 3 K / \mathrm{AKT}$ signalling [37]. In addition, the recent demonstration that mTORC1 inhibition increases RTK/IRS-1/PI3K activity towards Ras/MAPK [43] may provide a mechanistic explanation for how treatment with $2.5 \mu \mathrm{M}$ sorafenib also leads to ERK $1 / 2$ phosphorylation/activation. Together, these results demonstrate that the anti-proliferative effects of sorafenib were not dependent on its activity as a Raf1 inhibitor, but involved the inhibition of the mTORC1 pathway.

Combination of letrozole and sorafenib significantly enhanced the anti-proliferative activity compared with single agents alone in MCF7/AROM-1 cells as well as in T47D/AROM and BT474/AROM cells, with statistical analysis indicating synergistic interaction. The growthinhibitory effects produced by a 6-days combined treatment were maintained by an "upfront" schedule (a 3-days treatment with letrozole followed by 3 days of exposure to both drugs). Considering the advantage of shortening drug treatments, this result suggests that the "up-front" schedule may provide the optimal strategy for combining letrozole with sorafenib.

In MCF7/AROM-1 cells, the synergistic inhibition of cell proliferation was associated with accumulation of cells in the $G_{0} / G_{1}$ phase of the cell cycle and with down-regulation of cyclin D1, c-myc and phospho-Rb expression. In the experimental conditions adopted in 
the present study, both testosterone and serum growth factors contributed to sustain the expression of cyclin D1 and c-myc thus promoting cell proliferation. Estrogens induce the expression of these genes through a "non-classical" pathway in which ER binds to AP-1 proteins and functions as a coactivator to stimulate gene transcription [44]. Growth factormediated contribution to cyclin D1 and c-myc expression is quite complex and primarily involves the mTORC1 signalling cascade. In particular, mTORC1 can regulate the synthesis of both cyclin D1 and c-myc by controlling cap-dependent mRNA translation. However, when this pathway is inhibited, for example by rapamycin or sorafenib, translation can be initiated via IRES-mediated mechanisms [45]. Moreover, mTORC1 can induce cyclin $D 1$ and c-myc gene transcription by activating transcriptional factors such as STAT3 [46]. Since the regulation of these genes is governed by at least these two different mechanisms of control (ER-mediated genomic pathway and mTORC1 pathway), both have to be inhibited to reduce cyclin D1 and c-myc expression and to block cell cycle progression.

As previously mentioned, development of resistance to letrozole is a clinical issue. It has been reported that letrozole-resistant cell lines may be generated by prolonged culturing (more than 50 weeks) in the presence of the drug [38]. Research into the mechanism of endocrine responsiveness and resistance in breast cancer has revealed that various growth factor pathways, such as EGFR/HER2 or PI3K/AKT family, and oncogenes involved in the signal transduction cascades become activated and utilized by breast cancer cells to bypass the effects of endocrine treatments [47]. Such cascades would antagonize the anti-proliferative effect of anti-estrogens and thus represent attractive targets for pharmacologic intervention with signal transduction inhibitors that target aberrantly or excessively expressed oncogene products. Here we demonstrate that when letrozole is used in combination with sorafenib under long-term culture conditions (12 
weeks), the cell proliferation rate rapidly drops as compared with letrozole-treated cells, and the cells ultimately die.

In conclusion, to our knowledge, this is the first in vitro study demonstrating the efficacy of combining letrozole with the multi-kinase inhibitor sorafenib for the treatment of breast cancer either to inhibit cell growth or to prevent the acquisition of resistance to Als therapy. To prove the clinical benefits of the association of letrozole with sorafenib a phase II clinical trial in breast cancer neo-adjuvant setting is on-going between our Institutions. 
Acknowledgements: We thank Bayer HealthCare Pharmaceuticals for providing sorafenib 


\section{REFERENCES}

(1). Osborne CK, Shou J, Massarweh S, Schiff R. (2005) Crosstalk between estrogen receptor and growth factor receptor pathways as a cause for endocrine therapy resistance in breast cancer. Clin Cancer Res 11:865s-70s

(2). Bjornstrom L, Sjoberg M. (2005) Mechanisms of estrogen receptor signaling: convergence of genomic and nongenomic actions on target genes. Mol Endocrinol 19:83342

(3). Migliaccio A, Di Domenico M, Castoria G, et al. (1996) Tyrosine kinase/p21ras/MAP-kinase pathway activation by estradiol-receptor complex in MCF-7 cells. EMBO J 15:1292-300

(4). Le Goff P, Montano MM, Schodin DJ, Katzenellenbogen BS. (1994) Phosphorylation of the human estrogen receptor. Identification of hormone-regulated sites and examination of their influence on transcriptional activity. J Biol Chem 269:4458-66

(5). Kato S, Endoh H, Masuhiro Y, et al. (1995) Activation of the estrogen receptor through phosphorylation by mitogen-activated protein kinase. Science 270:1491-4

(6). Smith IE, Dowsett M. (2003) Aromatase inhibitors in breast cancer. N Engl J Med $348: 2431-42$

(7). Haynes BP, Dowsett M, Miller WR, Dixon JM, Bhatnagar AS. (2003) The pharmacology of letrozole. J Steroid Biochem Mol Biol 87:35-45

(8). Bhatnagar AS. (2006) Review of the development of letrozole and its use in advanced breast cancer and in the neoadjuvant setting. Breast 15 Suppl $1:$ S3-13

(9). Schiff R, Massarweh SA, Shou J, Bharwani L, Mohsin SK, Osborne CK. (2004) Cross-talk between estrogen receptor and growth factor pathways as a molecular target for overcoming endocrine resistance. Clin Cancer Res 10:331S-6S 
(10). Johnston SR, Martin LA, Leary A, Head J, Dowsett M. (2007) Clinical strategies for rationale combinations of aromatase inhibitors with novel therapies for breast cancer. $\mathrm{J}$ Steroid Biochem Mol Biol 106:180-6

(11). Gligorov J, Azria D, Namer M, Khayat D, Spano JP. (2007) Novel therapeutic strategies combining antihormonal and biological targeted therapies in breast cancer: focus on clinical trials and perspectives. Crit Rev Oncol Hematol 64:115-28

(12). Generali D, Buffa FM, Berruti A, et al. (2009) Phosphorylated ERalpha, HIF-1alpha, and MAPK signaling as predictors of primary endocrine treatment response and resistance in patients with breast cancer. J Clin Oncol 27:227-34

(13). Kane RC, Farrell AT, Saber H, et al. (2006) Sorafenib for the treatment of advanced renal cell carcinoma. Clin Cancer Res 12:7271-8

(14). Kane RC, Farrell AT, Madabushi R, et al. (2009) Sorafenib for the treatment of unresectable hepatocellular carcinoma. Oncologist 14:95-100

(15). Wilhelm SM, Carter C, Tang L, et al. (2004) BAY 43-9006 exhibits broad spectrum oral antitumor activity and targets the RAF/MEK/ERK pathway and receptor tyrosine kinases involved in tumor progression and angiogenesis. Cancer Res 64:7099-109

(16). Plaza-Menacho I, Mologni L, Sala E, et al. (2007) Sorafenib functions to potently suppress RET tyrosine kinase activity by direct enzymatic inhibition and promoting RET lysosomal degradation independent of proteasomal targeting. J Biol Chem 282:29230-40 (17). Sharma A, Trivedi NR, Zimmerman MA, Tuveson DA, Smith CD, Robertson GP. (2005) Mutant V599EB-Raf regulates growth and vascular development of malignant melanoma tumors. Cancer Res 65:2412-21

(18). Liu L, Cao Y, Chen C, et al. (2006) Sorafenib blocks the RAF/MEK/ERK pathway, inhibits tumor angiogenesis, and induces tumor cell apoptosis in hepatocellular carcinoma model PLC/PRF/5. Cancer Res 66:11851-8 
(19). Panka DJ, Wang W, Atkins MB, Mier JW. (2006) The Raf inhibitor BAY 43-9006 (Sorafenib) induces caspase-independent apoptosis in melanoma cells. Cancer Res $66: 1611-9$

(20). Huether A, Hopfner M, Baradari V, Schuppan D, Scherubl H. (2007) Sorafenib alone or as combination therapy for growth control of cholangiocarcinoma. Biochem Pharmacol 73:1308-17

(21). Rahmani M, Davis EM, Bauer C, Dent P, Grant S. (2005) Apoptosis induced by the kinase inhibitor BAY 43-9006 in human leukemia cells involves down-regulation of Mcl-1 through inhibition of translation. J Biol Chem 280:35217-27

(22). Ding Q, Huo L, Yang JY, et al. (2008) Down-regulation of myeloid cell leukemia-1 through inhibiting Erk/Pin 1 pathway by sorafenib facilitates chemosensitization in breast cancer. Cancer Res 68:6109-17

(23). Huynh H, Ngo VC, Koong HN, et al. (2009) Sorafenib and Rapamycin Induce Growth Suppression in Mouse Models of Hepatocellular Carcinoma. J Cell Mol Med DOI: 10.1111/j.1582-4934.2009.00692.x

(24). Kumar SM, Yu H, Edwards R, et al. (2007) Mutant V600E BRAF increases hypoxia inducible factor-1alpha expression in melanoma. Cancer Res 67:3177-84

(25). Macaulay VM, Nicholls JE, Gledhill J, Rowlands MG, Dowsett M, Ashworth A. (1994) Biological effects of stable overexpression of aromatase in human hormonedependent breast cancer cells. Br J Cancer 69:77-83

(26). Banerjee S, Zvelebil M, Furet P, et al. (2009) The vascular endothelial growth factor receptor inhibitor PTK787/ZK222584 inhibits aromatase. Cancer Res 69:4716-23

(27). Cavazzoni A, Petronini PG, Galetti M, et al. (2004) Dose-dependent effect of FHITinducible expression in Calu-1 lung cancer cell line. Oncogene 23:8439-46 
(28). Fumarola C, La Monica S, Alfieri RR, Borra E, Guidotti GG. (2005) Cell size reduction induced by inhibition of the mTOR/S6K-signaling pathway protects Jurkat cells from apoptosis. Cell Death Differ 12:1344-57

(29). Goldoni M, Johansson C. (2007) A mathematical approach to study combined effects of toxicants in vitro: evaluation of the Bliss independence criterion and the Loewe additivity model. Toxicol In Vitro 21:759-69

(30). La Monica S, Galetti M, Alfieri RR, et al. (2009) Everolimus restores gefitinib sensitivity in resistant non-small cell lung cancer cell lines. Biochem Pharmacol 78:460-8

(31). Aesoy R, Sanchez BC, Norum JH, Lewensohn R, Viktorsson K, Linderholm B. (2008) An autocrine VEGF/VEGFR2 and p38 signaling loop confers resistance to 4hydroxytamoxifen in MCF-7 breast cancer cells. Mol Cancer Res 6:1630-8

(32). Lathia C, Lettieri J, Cihon F, Gallentine M, Radtke M, Sundaresan P. (2006) Lack of effect of ketoconazole-mediated CYP3A inhibition on sorafenib clinical pharmacokinetics. Cancer Chemother Pharmacol 57:685-92

(33). Strumberg D, Clark JW, Awada A, et al. (2007) Safety, pharmacokinetics, and preliminary antitumor activity of sorafenib: a review of four phase I trials in patients with advanced refractory solid tumors. Oncologist 12:426-37

(34). Gatti R, Belletti S, Orlandini G, Bussolati O, Dall'Asta V, Gazzola GC. (1998) Comparison of annexin $\mathrm{V}$ and calcein-AM as early vital markers of apoptosis in adherent cells by confocal laser microscopy. J Histochem Cytochem 46:895-900

(35). Kagawa S, Gu J, Honda T, et al. (2001) Deficiency of caspase-3 in MCF7 cells blocks Bax-mediated nuclear fragmentation but not cell death. Clin Cancer Res 7:1474-80 (36). Oliver FJ, de la Rubia G, Rolli V, Ruiz-Ruiz MC, de Murcia G, Murcia JM. (1998) Importance of poly(ADP-ribose) polymerase and its cleavage in apoptosis. Lesson from an uncleavable mutant. J Biol Chem 273:33533-9 
(37). O'Reilly KE, Rojo F, She QB, et al. (2006) mTOR inhibition induces upstream receptor tyrosine kinase signaling and activates Akt. Cancer Res 66:1500-8

(38). Belosay A, Brodie AM, Njar VC. (2006) Effects of novel retinoic acid metabolism blocking agent (VN/14-1) on letrozole-insensitive breast cancer cells. Cancer Res $66: 11485-93$

(39). Wilhelm S, Chien DS. (2002) BAY 43-9006: preclinical data. Curr Pharm Des 8:2255-7

(40). Yu C, Bruzek LM, Meng XW, et al. (2005) The role of Mcl-1 downregulation in the proapoptotic activity of the multikinase inhibitor BAY 43-9006. Oncogene 24:6861-9

(41). Tran MA, Smith CD, Kester M, Robertson GP. (2008) Combining nanoliposomal ceramide with sorafenib synergistically inhibits melanoma and breast cancer cell survival to decrease tumor development. Clin Cancer Res 14:3571-81

(42). Molhoek KR, Brautigan DL, Slingluff CL, Jr. (2005) Synergistic inhibition of human melanoma proliferation by combination treatment with B-Raf inhibitor BAY43-9006 and mTOR inhibitor Rapamycin. J TransI Med 3:39

(43). Carracedo A, Ma L, Teruya-Feldstein J, et al. (2008) Inhibition of mTORC1 leads to MAPK pathway activation through a PI3K-dependent feedback loop in human cancer. $\mathrm{J}$ Clin Invest 118:3065-74

(44). DeNardo DG, Cuba VL, Kim H, Wu K, Lee AV, Brown PH. (2007) Estrogen receptor DNA binding is not required for estrogen-induced breast cell growth. Mol Cell Endocrinol 277:13-25

(45). Shi Y, Sharma A, Wu H, Lichtenstein A, Gera J. (2005) Cyclin D1 and c-myc internal ribosome entry site (IRES)-dependent translation is regulated by AKT activity and enhanced by rapamycin through a p38 MAPK- and ERK-dependent pathway. J Biol Chem 280:10964-73 
(46). Zhou J, Wulfkuhle J, Zhang $\mathrm{H}$, et al. (2007) Activation of the PTEN/mTOR/STAT3 pathway in breast cancer stem-like cells is required for viability and maintenance. Proc Natl Acad Sci U S A 104:16158-63

(47). Nicholson RI, McClelland RA, Robertson JF, Gee JM. (1999) Involvement of steroid hormone and growth factor cross-talk in endocrine response in breast cancer. Endocr Relat Cancer 6: 373-87 


\section{FIGURE LEGENDS}

Fig.1 MCF-7/AROM-1 cell proliferation is stimulated by estrogens and inhibited by letrozole and sorafenib

a, Steroid-deprived cells $\left(10^{4} \mathrm{cells} / \mathrm{cm}^{2}\right)$ were treated with E2 or T up to $144 \mathrm{~h}$. Cell proliferation was assessed by MTT assay. Data are expressed as fold increase versus steroid-deprived cells.

b, Cells were seeded at the indicated density in 96-multiwell plates and 24h later were treated with $\mathrm{T}$ in the absence or presence of increasing concentrations of letrozole. After 6 days of incubation cell proliferation was assessed by MTT assay.

c, Steroid-deprived cells $\left(10^{4} \mathrm{cells} / \mathrm{cm}^{2}\right)$ were treated with $\mathrm{T}$ in the absence or presence of increasing concentrations of sorafenib $(0.1-5 \mu \mathrm{M})$. After 6 days cell proliferation was assessed by MTT assay. The $\mathrm{IC}_{50}$ value, calculated as reported in Material and Methods, was of $3 \mu \mathrm{M}$.

Data in $b$ and $c$ are expressed as percent of inhibition of cell proliferation versus Tstimulated cells. Columns, means of three separate experiments; bars, SD. ${ }^{*} \mathrm{p}<0.05$; ${ }^{* *} \mathrm{p}<0.01$.

$\mathrm{d}$, Cells were pre-incubated for $30 \mathrm{~min}$ with sorafenib $(\mathrm{S}, 1-10 \mu \mathrm{M})$ and then stimulated with $\mathrm{T}$ for $2 \mathrm{~h}$ in the absence or presence of the drug at the indicated concentrations. The cells were lysed and protein expression was assessed by Western blot analysis. Data are from a representative experiment. Each experiment, repeated three times, yielded similar results.

Fig. 2 Sorafenib at high concentrations induces cell death by apoptosis 
Steroid-deprived MCF-7/AROM-1 cells were treated with $\mathrm{T}$ in the absence or presence of various concentrations of sorafenib $(\mathrm{S}, 1-10 \mu \mathrm{M})$ up to $72 \mathrm{~h}$.

a, Cell death was quantitated at the indicated time intervals by fluorescence microscopy on Hoechst 33342/PI-stained cells. Data are expressed as percent values. Columns, means of three separate experiments; bars, SD. ${ }^{*} \mathrm{p}<0.05 ;{ }^{* *} \mathrm{p}<0.01$.

b, Morpho-functional analysis of cell death was evaluated by real time CLSM after $48 \mathrm{~h}$ of treatment with sorafenib $10 \mu \mathrm{M}$ using the vital stain calcein-AM (green colour), and the nuclear dyes Draq5 (blue colour) and PI (red colour) to discriminate between viable/early apoptotic and dead cells. Arrows, blebs; arro wheads, calcein-AM positivity until late stages of cell death. Bar, $20 \mu \mathrm{m}$.

C, Cleavage of PARP-1, procaspase- $8,-9$ and -7 were assessed at the indicated time by Western blot analysis.

d, Cytochrome $c$ and AIF release from mitochondria was assessed after 24 and $48 \mathrm{~h}$ of incubation with sorafenib $10 \mu \mathrm{M}$ by Western blot analysis of cell cytosolic and mitochondrial fractions.

Images shown in b and results presented in $\mathrm{c}$ and $\mathrm{d}$ are from a representative experiment. Each experiment, repeated three times, yielded similar results.

Fig. 3 Combination of letrozole and sorafenib potentiates the inhibition of cell proliferation a, Steroid-deprived MCF-7/AROM-1 cells $\left(10^{4} \mathrm{cells} / \mathrm{cm}^{2}\right)$ were treated with $\mathrm{T}$ in the absence or presence of $1 \mu \mathrm{M}$ letrozole combined with various concentrations of sorafenib $(0.1-5 \mu M)$. After 6 days cell proliferation was assessed by MTT assay and the effect of the drug combination was evaluated using the Bliss interaction model. Data are expressed as percent of inhibition of cell proliferation versus T-stimulated cells and are means of three separate experiments. Bars, SD. ${ }^{*} p<0.05 ;{ }^{* *} p<0.01$. 
b, Cells $\left(10^{4} \mathrm{cells} / \mathrm{cm}^{2}\right)$ were treated for 6 days with $\mathrm{T}$ in the absence or presence of $1 \mu \mathrm{M}$ letrozole (L1), $2.5 \mu \mathrm{M}$ sorafenib (S2.5) or three different combinations of the drugs: 6 days of continuous exposure to letrozole and sorafenib $(L+S)$; a 3 days-treatment with letrozole followed by a 3 days-treatment with sorafenib ( $L$ before $S$ ); a 3 days-treatment with letrozole followed by 3 days of combined treatment $(L$ before $L+S)$. Cell proliferation was assessed by MTT assay. Data are expressed as percent of inhibition of cell proliferation versus T-stimulated cells. Columns, means of three separate experiments; bars, SD. ${ }^{*} \mathrm{p}<0.05 ;{ }^{* *} \mathrm{p}<0.01$ (one-way ANOVA).

c, Cells were treated with $\mathrm{T}$ in the absence or presence of $1 \mu \mathrm{M}$ letrozole $(\mathrm{L}), 2.5 \mu \mathrm{M}$ sorafenib (S) or the combination of both. The cells were lysed at the indicated time and protein expression was assessed by Western blot analysis. The results are from a representative experiment. Each experiment, repeated three times, yielded similar results.

Fig. 4 Combination of letrozole and sorafenib produces a synergistic inhibition of cell proliferation in T47D/AROM and BT474/AROM cells

Steroid-deprived cells $\left(10^{4} \mathrm{cells} / \mathrm{cm}^{2}\right)$ were treated with $\mathrm{T}$ in the absence or presence of increasing concentrations of letrozole (a) or sorafenib (b). After 6 days of incubation cell proliferation was assessed by MTT assay. Data are expressed as percent of inhibition of cell proliferation versus T-stimulated cells. Columns, means of three separate experiments; bars, SD. ${ }^{*} p<0.05 ;{ }^{*} \mathrm{p}<0.01$.

c, Steroid-deprived cells were treated with $T$ in the absence or presence of various concentrations of sorafenib up to $72 \mathrm{~h}$. Cell death was quantitated by fluorescence microscopy on Hoechst 33342/PI-stained cells. Data are expressed as percent values. Columns, means of three separate experiments; bars, SD. ${ }^{*} p<0.05 ;{ }^{* *} p<0.01$.

d, Steroid-deprived cells $\left(10^{4} \mathrm{cells} / \mathrm{cm}^{2}\right)$ were treated with $\mathrm{T}$ in the absence or presence of letrozole ( $1 \mu \mathrm{M}$ for T47D/AROM clone 1 and $2 ; 10^{-2} \mu \mathrm{M}$ for BT474/AROM cells) combined 
with increasing concentrations of sorafenib. After 6 days cell proliferation was assessed by MTT assay and the effect of the drug combination was evaluated using the Bliss interaction model. Data are expressed as percent of inhibition of cell proliferation versus Tstimulated cells and are means of three separate experiments. Bars, SD. ${ }^{*} p<0.05$; ${ }^{* *} \mathrm{p}<0.01$.

Fig. 5 Letrozole and sorafenib cooperate to inhibit cell cycle progression in $\mathrm{G}_{1}$ phase Steroid-deprived MCF-7/AROM-1 cells were untreated (without steroids) or treated with T in the absence or presence of $1 \mu \mathrm{M}$ letrozole (L1), $2.5 \mu \mathrm{M}$ sorafenib (S2.5) or a combination of both.

a, After $72 \mathrm{~h}$ the cells were analyzed by flow cytometry for cell cycle-phase distribution. Mean percentages $\pm S D$ of cells residing in each cycle phase are reported in the table ( ${ }^{*} \mathrm{p}<0.05 ;{ }^{* *} \mathrm{p}<0.01$, Student's $t$ test versus T-stimulated cells; \#\#\# $\mathrm{p}<0.001$, one-way ANOVA versus single agent treatment).

$\mathrm{b}$, After $72 \mathrm{~h}$ of treatment the cells were lysed and protein expression was assessed by Western blot analysis. R: rapamycin. The results are from a representative experiment. Each experiment, repeated three times, yielded similar results.

Fig. 6 Effect of long-lasting treatments with letrozole and sorafenib on MCF-7/AROM-1 cell proliferation

MCF-7/AROM-1 T-stimulated cells were continuously cultured in the presence of $1 \mu \mathrm{M}$ letrozole (L1), $2.5 \mu \mathrm{M}$ sorafenib (S2.5), or the combination of both $(\mathrm{L} 1+\mathrm{S} 2.5)$ up to 12 weeks. Once a week the cells were counted and reseeded at the density of $8 \times 10^{3}$ cells $/ \mathrm{cm}^{2}$. Data are expressed as proliferation index $\mathrm{N} / \mathrm{N}_{0}$, where $\mathrm{N}$ is the number of cells counted after 7 days of culture and $\mathrm{N}_{0}$ is the number of cells initially seeded. 
Bonelli MA Fig. 1

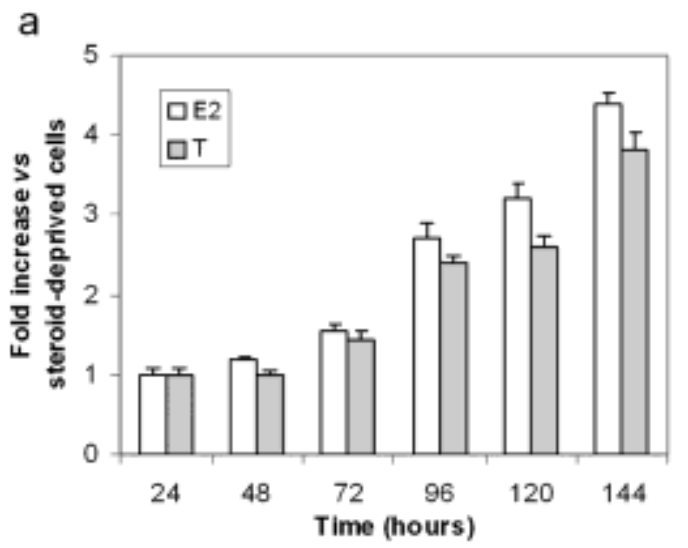

C

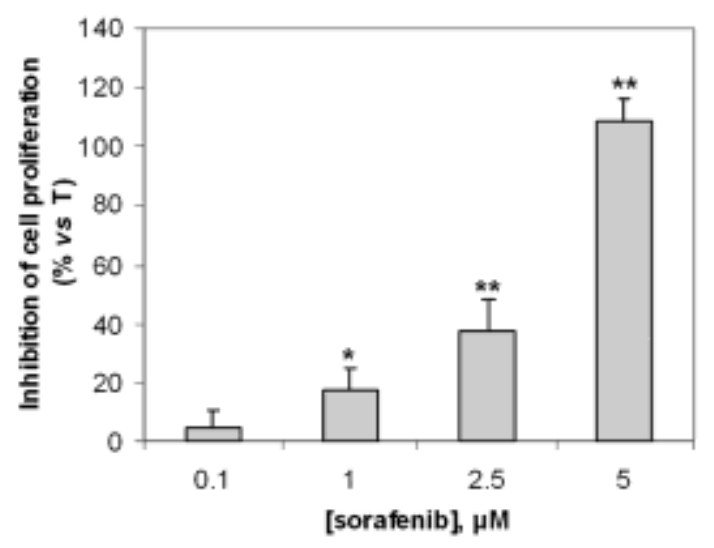

b

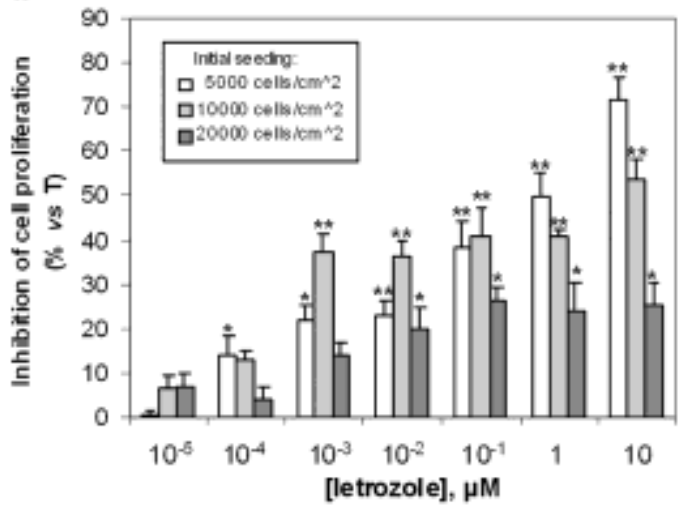

d

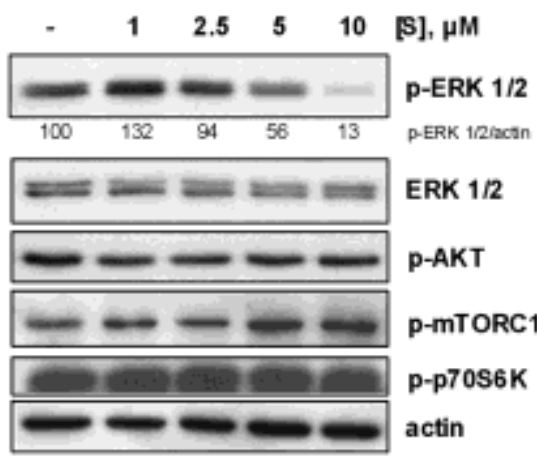


Bonelli MA Fig. 2

a

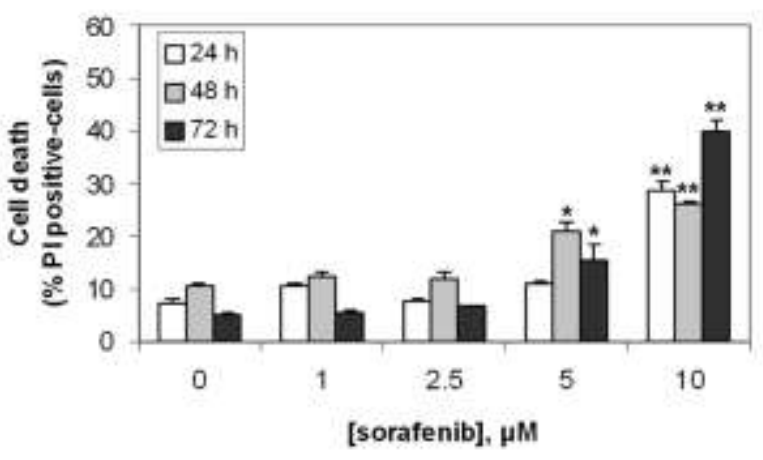

b

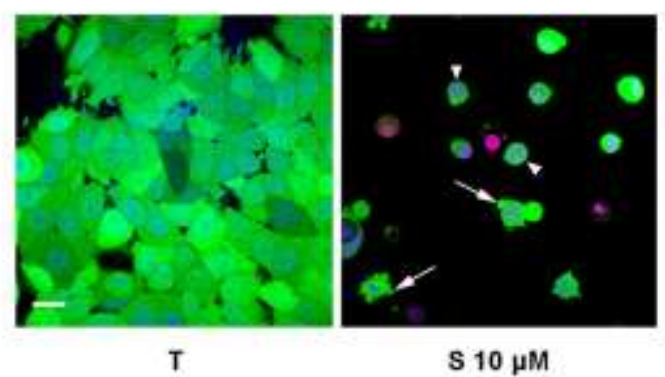

C

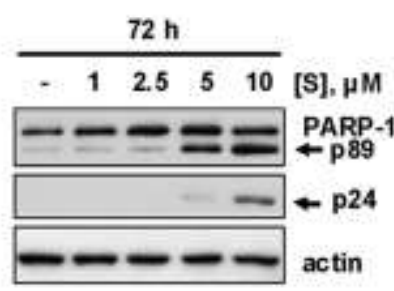

$48 \mathrm{~h}$

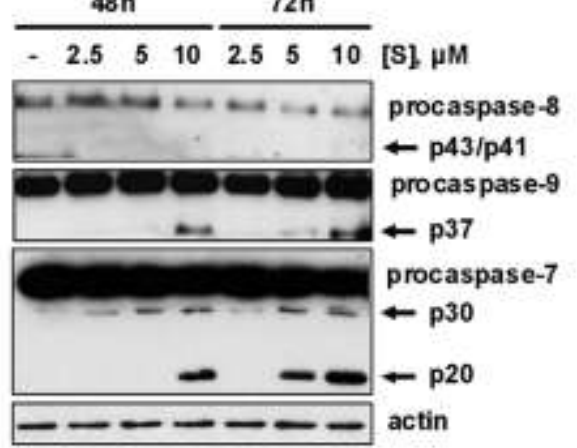

d

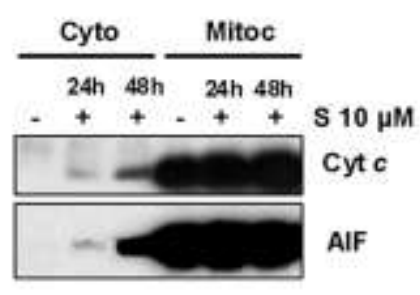


Bonelli MA Fig. 3

a

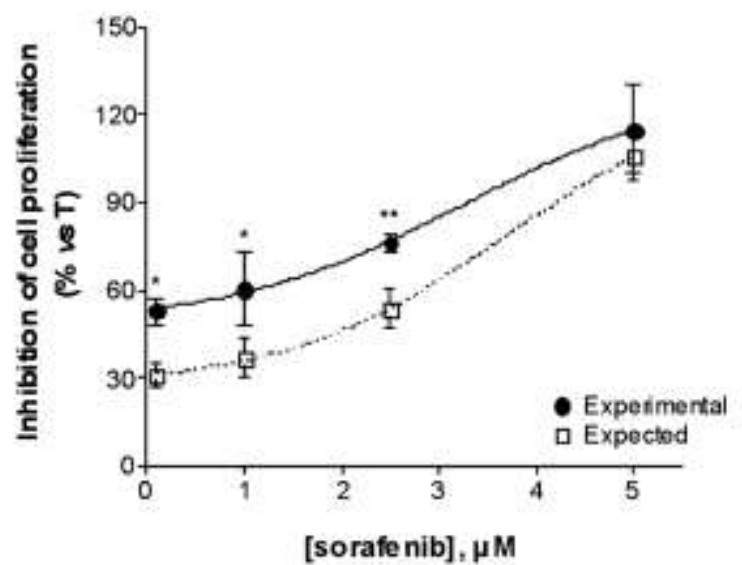

b

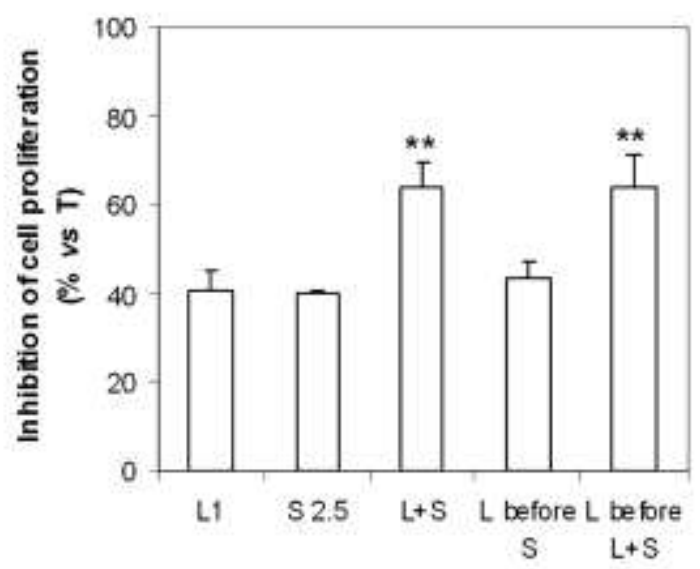

C
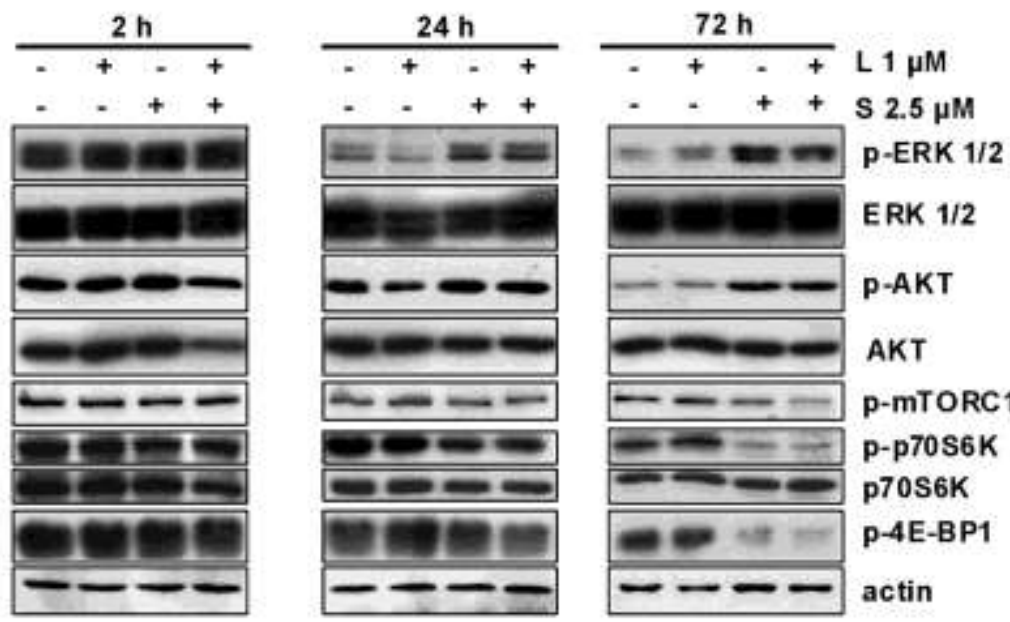
Bonelli MA Fig.4

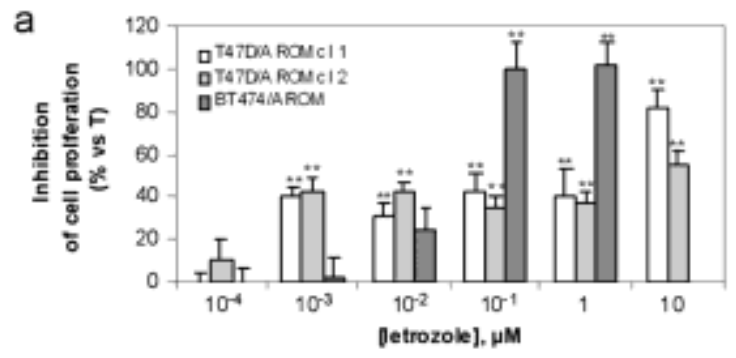

b
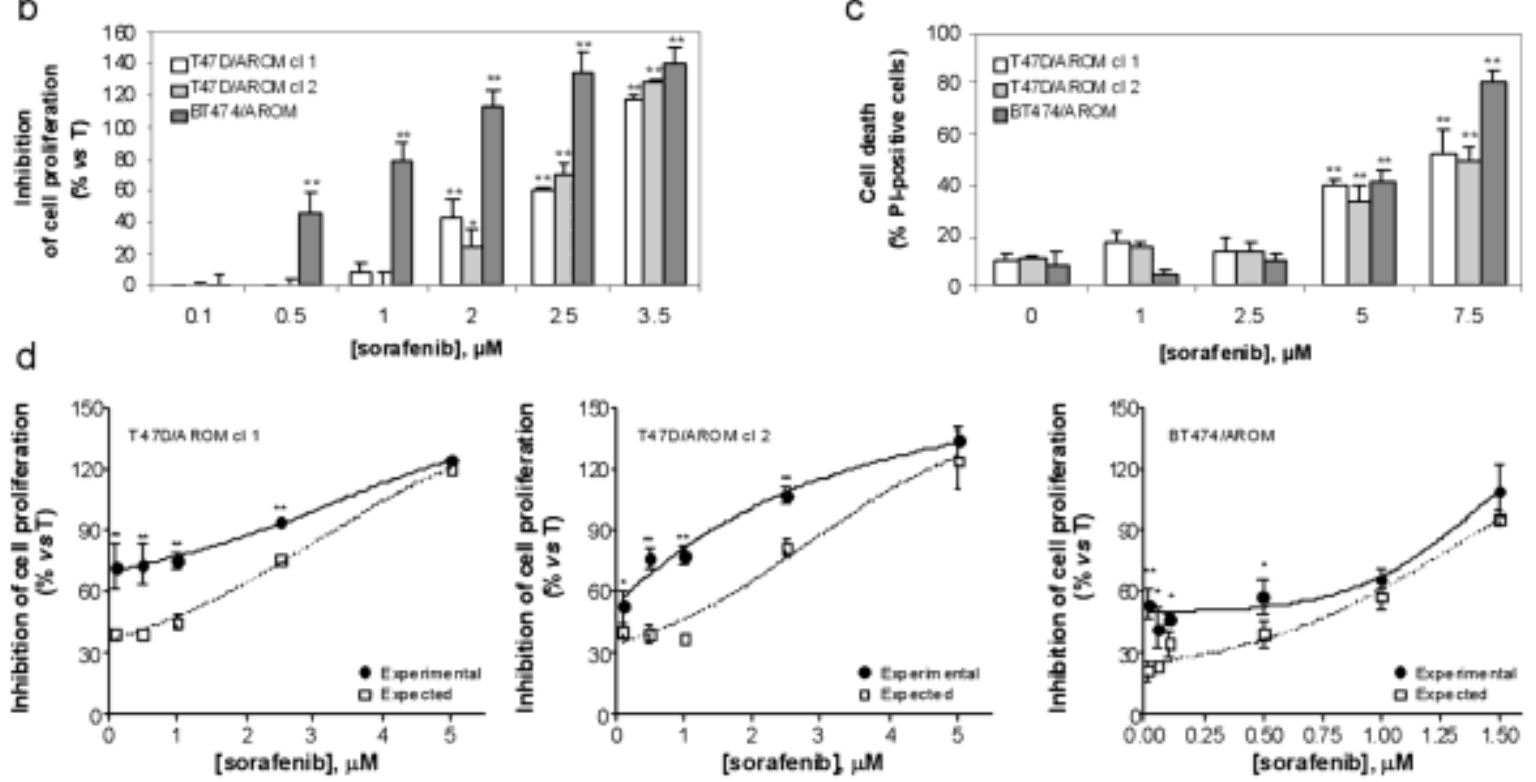

Bonelli MA Fig. 5

\begin{tabular}{lccc}
\hline & $\mathrm{G}_{0} / \mathrm{G}_{1}$ & $\mathrm{~S}$ & $\mathrm{G}_{2} / \mathrm{M}$ \\
\hline $\begin{array}{l}\text { w/o } \\
\text { steroids }\end{array}$ & $88 \pm 1.7$ & $6 \pm 1.5$ & $6 \pm 1.1$ \\
\hline $\mathrm{T}$ & $63 \pm 1.5$ & $27 \pm 0.6$ & $11 \pm 1.5$ \\
\hline $\mathrm{L} 1$ & $73 \pm 2^{*}$ & $17 \pm 2.1$ & $10 \pm 1.5$ \\
\hline $\mathrm{S} 2.5$ & $70 \pm 1.1^{*}$ & $21 \pm 0.6$ & $9 \pm 1$ \\
\hline $\mathrm{L} 1+\mathrm{S} 2.5$ & $81 \pm 0.6 \pm$ & $11 \pm 1.5$ & $7 \pm 0.6$ \\
\hline
\end{tabular}

b

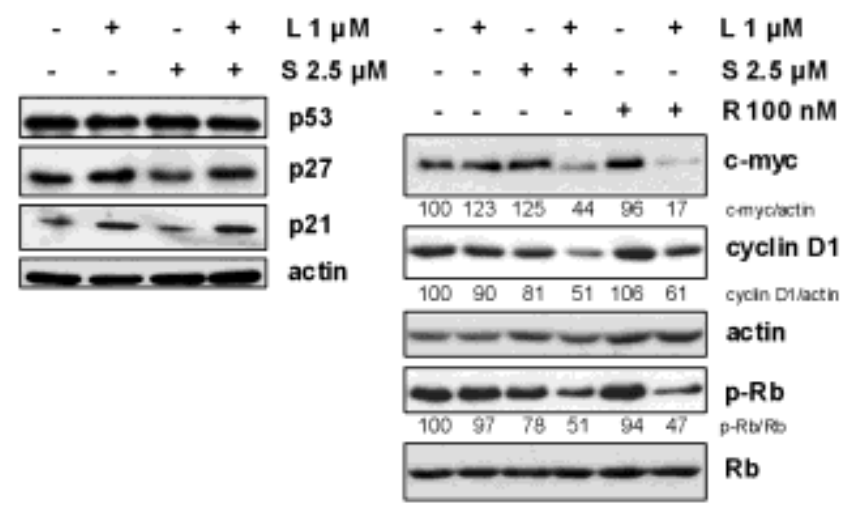


Bonelli MA Fig.6

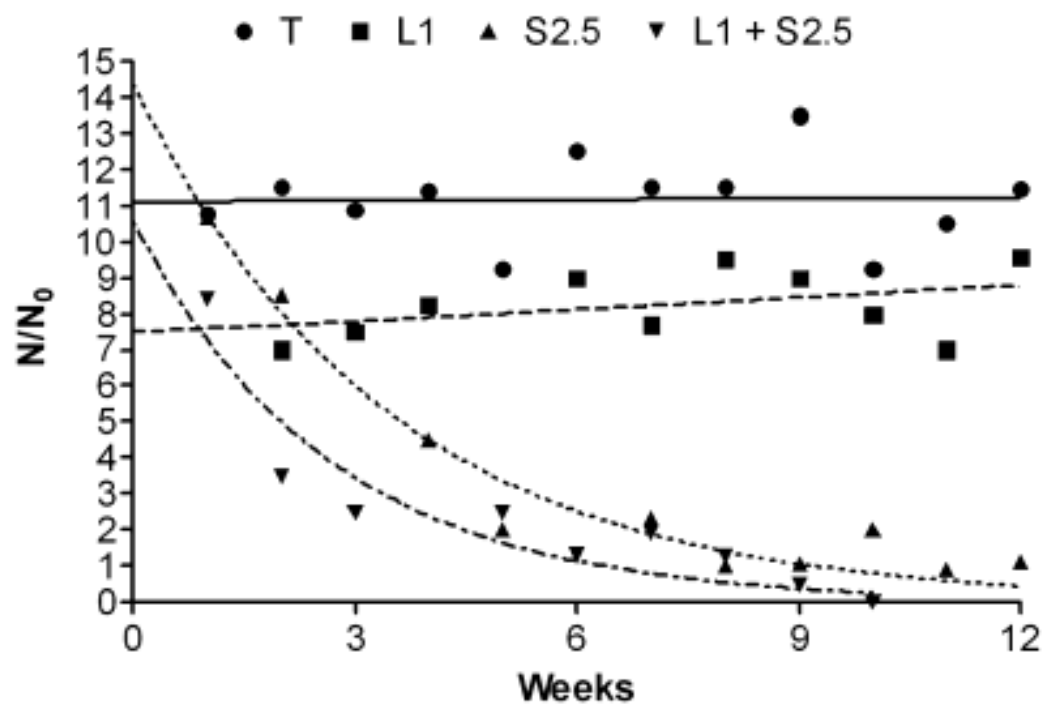

Dean Evans is employed by Novartis Pharma AG. 